Check for updates

Cite this: RSC Adv., 2021, 11, 21097

Received 16th April 2021

Accepted 6th June 2021

DOI: $10.1039 / \mathrm{d} 1 \mathrm{ra02979g}$

rsc.li/rsc-advances

\section{First thermal studies on visible-light-switchable negative T-type photochromes of a nitrile-rich series $\uparrow$}

\begin{abstract}
Mikhail Yu. Belikov (D)* and Mikhail Yu. levlev (D)
Representatives of visible-light-switchable nitrile-rich negative T-type photochromes (NRP) were synthesized. The temperature effect on the thermal relaxation of the photoinduced form of NRP was studied for the first time. It was found that regardless the temperature the reverse thermal reaction in ethanol and 1,4-dioxane proceeded according to a first-order kinetic equation, while an unusual pseudo-zero order of the dark reaction was observed in acetonitrile. Using the obtained experimental data, the activation energy as well as the activation parameters, such as entropy and enthalpy of activation, were calculated for the first time for thermal relaxation of NRP photochromes. It was also shown that an initial form of NRP photochromes bearing a tricyanofuran acceptor was more temperature resistant than the initial form of photochromes with a tricyanopyrrole acceptor.
\end{abstract}

\section{Introduction}

Photochromic compounds are an intensively studied group of molecules due to their wide range of practical application. They are used in optically functionalized organic field-effect transistors $(\mathrm{OFET})^{1}$ and nanosystems, ${ }^{2}$ and as multiaddressable architectures, ${ }^{3}$ solar thermal fuels, ${ }^{4}$ fluorophores at the molecular and nanoparticle levels, ${ }^{5}$ and all-visible-light-triggered materials ${ }^{6}$ as well as in biological research..$^{7-9}$

Ultraviolet or visible light irradiation causes a reversible transformation of photochromes A into a metastable photoinduced form B (Fig. 1). It should be noted that studies of photochromes with the possibility to use visible light only ${ }^{6}$ as a nondestructive and selective trigger to control the properties of substances and materials are intensified nowadays. Depending on a chromaticity of transformations direct and negative photochromism are distinguished. In the first case, the initial form $\mathbf{A}$ absorbs shorter wavelengths than photoinduced form $\mathbf{B}$ which is generally deeply colored. In contrary, for the negative photochromes the initial form $\mathbf{A}$ absorbs longer wavelengths, and the form $\mathbf{B}$ is less colored or completely colorless. It has been noted ${ }^{10,11}$ that negative photochromes are much less common and therefore poorly studied.

The photoinduced form $\mathbf{B}$ can be stable during a long period at dark conditions (P-type photochromism), or it spontaneously returns to the initial state $\mathbf{A}$ at room or raised temperature ( $\mathrm{T}$ type photochromism). ${ }^{12-14}$ In the case of T-type photochromes,

Ulyanov Chuvash State University, Moskovsky pr., 15, Cheboksary, Russia 428015. E-mail: belikovmil@mail.ru

$\dagger$ Electronic supplementary information (ESI) available. See DOI: 10.1039/d1ra02979g this feature is important and exciting because it allows to control the stability of the photoinduced form by changing the temperature conditions. This issue has been well studied for

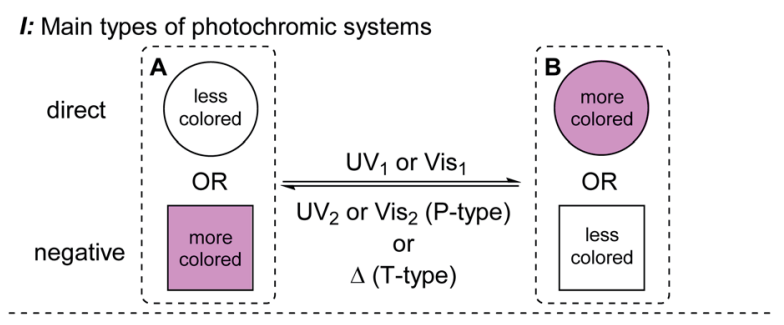

II: A poorly-studied group of nitrile-rich negative photochromes (NRP)

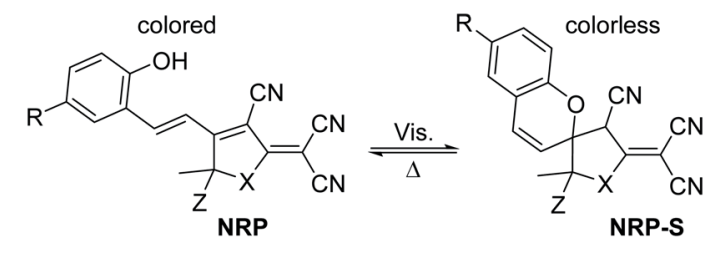

III: This work

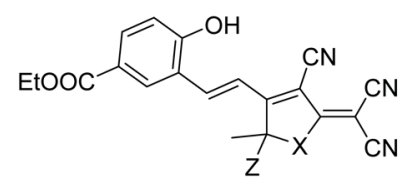

1

Studied for the first time for NRP group:

Temperature and solvent effects on the reverse reaction rate

Thermodymanic parameters of the reverse reaction

Thermal stability

Fig. 1 Known photochromic systems and the object of the presented work. 
known groups of photochromes, such as spiropyrans, ${ }^{15,16}$ spirooxazines, ${ }^{17}$ azobenzenes, ${ }^{18,19}$ diarylethenes, ${ }^{20,21}$ dihydropyrene,$^{22}$ dihydroindolizines ${ }^{23}$ and bindone derivatives. ${ }^{24}$

Papers ${ }^{15-24}$ also demonstrate that the analysis of the temperature effect on the rate constant allows to estimate various important energy parameters of the reverse thermal reaction of photochromes, for example activation energy.

Compounds bearing a nitrile-rich acceptor and $\delta$-OH-group in the same molecule are a relatively poorly studied group of negative photochromes (NRP, Fig. 1). ${ }^{25-31}$

NRP derivatives show photochromism under irradiation by visible light. Their colored initial form is converted into a colorless spiran NRP-S. The reverse reaction occurs when the solutions is stored in the dark, characterizing NRP derivatives as T-type photochromes. The importance of a more detailed study of this group of photochromes is supported by the fact that the possibility for photo-regulation of acidic ${ }^{25,26}$ and fluorescent ${ }^{27}$ properties of some representatives has been reported, that indicates the prospects of their practical application.

It should be noted that, despite the reported data on the Ttype photochromism of NPR structures, there is no information in the literature about the temperature effect on the process of dark thermal relaxation of the photoinduced NRP-S form. Therefore, the thermodynamic parameters of this process are also unknown. Thus, the aim of this work is to investigate the influence of temperature on the dark reaction rate of photochromes $\mathbf{1}$, as well as to obtain the data on the thermal stability of NRP photochromes in an individual form.

\section{Results and discussion}

\subsection{Synthesis and structure determination}

To investigate temperature effect on the stability of the photoinduced form of NRP derivatives, it was necessary to select a convenient model object whose dark reverse reaction rate was easy to register both at decreased and raised temperature. We used our reported correlation between the Hammett constants $\sigma^{+}$for the substituent in the aryl ring and the observed half-lives $\left(\tau_{1 / 2}\right)$ of the photoinduced NRP-S form. ${ }^{28}$ According to these data, electron-donating and halogen substituents caused rather small $\tau_{1 / 2}$ values at room temperature, and electronwithdrawing groups slowed down the dark reaction. Thus, we chose photochrome 1a bearing an ester group in the phenolic ring as the most convenient object. The half-life period of the photoinduced NRP-S form of this compound was about 85
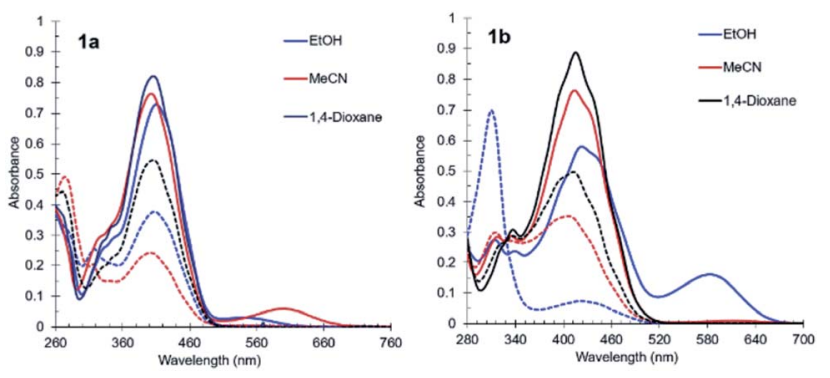

Fig. 2 UV-Vis spectra of compounds $1 \mathrm{a}$ and $1 \mathrm{~b}$ in ethanol (blue), acetonitrile (red) and 1,4-dioxane (black) before (solid line) and after (dashed line) visible light irradiation for $1 \mathrm{~min}\left(\mathrm{C}=2.5 \times 10^{-5} \mathrm{M}, 20^{\circ} \mathrm{C}\right.$ ).

seconds in ethanol at room temperature, that was considered as convenient for further investigations.

Also, a previously undescribed compound $\mathbf{1 b}$, bearing a furan ring in the structure as a nitrile-rich heterocyclic unit, was chosen as a second study object. The synthesis of these two compounds 1 was based on the interaction of the corresponding tricyano-substituted acceptors $\mathbf{2 a}$ and $\mathbf{2 b}$ with ethyl 3formyl-4-hydroxybenzoate in ethanol in the presence of ammonium acetate under an argon atmosphere (Scheme 1) giving $62-76 \%$ isolated yield. Structure of compounds 1 was supported with IR-, NMR spectroscopy and mass-spectrometry.

\subsection{Investigation of the photochromic properties}

Investigation of the temperature effect on the rate of dark reaction of photochromes $\mathbf{1}$ was carried out using UV-Vis spectroscopy. The absorption spectra of compounds 1 were registered in different solvents as ethanol, acetonitrile and 1,4dioxane. Fig. 2 shows the absorption spectra of NRP 1a,b before and after irradiation by visible light at $20{ }^{\circ} \mathrm{C}$. The absorption spectra are characterized with intense bands in the visible region centered in the range of 404-410 $\mathrm{nm}$ for pyrrole 1a and 414-424 $\mathrm{nm}$ for furan $\mathbf{1 b}$. There is also a second small band in the longer wavelength region of the spectrum in the range of 535-602 nm, corresponding to the quinoid form of compounds 1.

Fig. 2 shows that after visible light irradiation an absorption band in the visible region is decreased indicating a negative photochromic process for compounds 1 in each solvent (Table 1).

Depending on the solvent, the photoconversion of the initial form 1 into the photoinduced one is different, for example, for

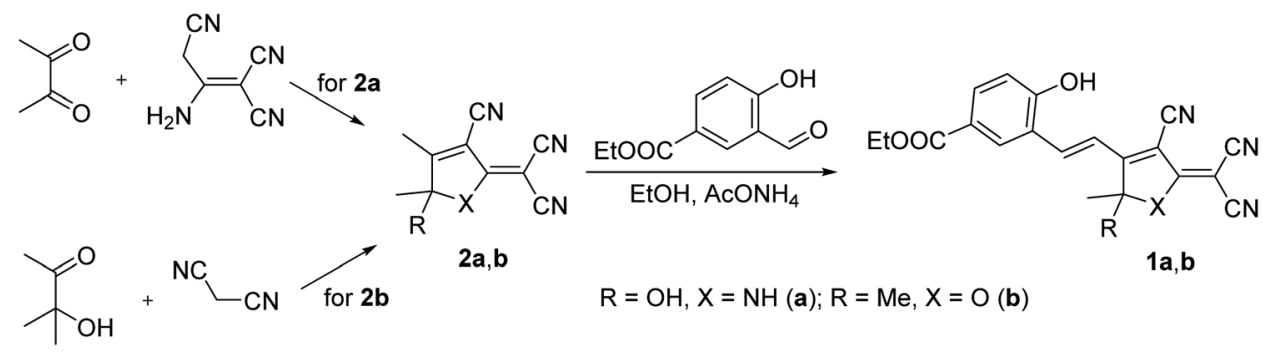

Scheme 1 Synthesis of compounds 1a,b. 
Table 1 Light absorption and photochromic characteristics of compounds $1 \mathrm{a}, \mathrm{b}$ at $20^{\circ} \mathrm{C}$

\begin{tabular}{|c|c|c|c|c|c|c|}
\hline Compound & Solvent & $\lambda_{\mathrm{abs}}^{\max }(\mathrm{nm})$ & $\varepsilon \times 10^{4}\left(\mathrm{~L} \times \mathrm{mol}^{-1} \times \mathrm{cm}^{-1}\right)$ & Abs & $\mathrm{AbS}_{\mathrm{PSS}}$ & $\mathrm{PC}^{a}(\%)$ \\
\hline \multirow[t]{4}{*}{ 1a } & EtOH & 410 & 2.92 & 0.730 & 0.376 & 48 \\
\hline & & 535 & 0.12 & 0.030 & 0.005 & \\
\hline & & 602 & 0.24 & 0.059 & - & \\
\hline & 1,4-Dioxane & 406 & 3.28 & 0.820 & 0.547 & 33 \\
\hline \multirow[t]{2}{*}{$1 \mathbf{b}$} & EtOH & 424 & 2.32 & 0.579 & 0.072 & 87 \\
\hline & 1,4-Dioxane & 415 & 3.54 & 0.886 & 0.494 & 44 \\
\hline
\end{tabular}
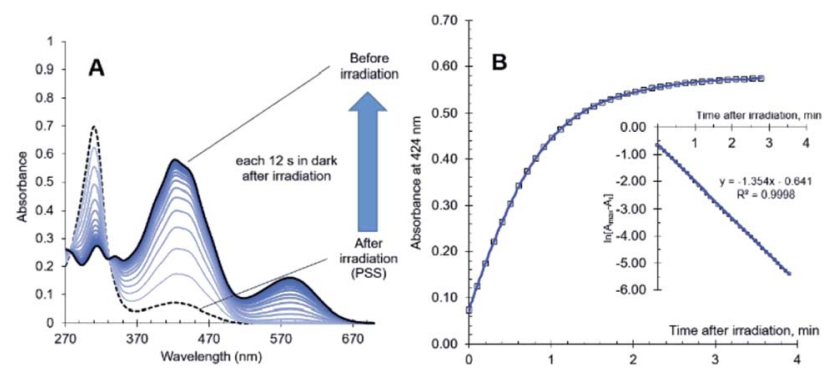

Fig. 3 UV-Vis spectra (A) and kinetics of the dark reverse reaction, $\lambda_{\text {abs }}$ $=424 \mathrm{~nm}$ (B) of the compound $1 \mathrm{~b}$ before and after irradiation (EtOH, C $=2.5 \times 10^{-5} \mathrm{M}, 20^{\circ} \mathrm{C}$ ).

furan $1 \mathrm{~b}$ it changes from $87 \%$ in ethanol to $44 \%$ in 1,4 -dioxane. Then, the absorption spectra of photochromes $\mathbf{1 a}, \mathbf{b}$ were registered at various temperatures in each of three solvents before and after irradiation. Fig. 3A shows the absorption spectra of compound $\mathbf{1 b}$ in ethanol before and after irradiation in dynamics at $20^{\circ} \mathrm{C}$.

Fig. 3A shows that the intensity of the band at $424 \mathrm{~nm}$ was significantly decreased under irradiation by visible light. After the irradiation had been stopped, the solution was storing in dark conditions and the absorbance was gradually returning to the initial value. Fig. 3B shows first-order kinetics of the dark thermal transformation of compound $\mathbf{1 b}$ after irradiation by visible light in ethanol.

\subsection{Investigation of the temperature effect on the thermal relaxation of the photoinduced form}

We observed that the rate of the dark reaction changes significantly depending on the temperature. For example, the half-life $\tau_{1 / 2}$ of the photo-induced form of pyrrole 1a in ethanol could be changed by more than 15 times from $8.3 \mathrm{~min}$ to $0.5 \mathrm{~min}$ (Table 2) upon changing the temperature from 10 to $30{ }^{\circ} \mathrm{C}$. A similar dependence in ethanol was observed for furan derivative $\mathbf{1 b}$.

Investigation of the temperature effect in 1,4-dioxane showed a significant difference in the rate of reverse reaction for compounds 1a and $\mathbf{1 b}$ (Fig. 4). Thus, the half-life period $\left(\tau_{1 / 2}\right)$ of $\mathbf{1 a}$ is $23.2 \mathrm{~min}$ and for furan $\mathbf{1 b}$ it is $\mathbf{0 . 4} \mathrm{min}$ only (Table 2) at
Table 2 Solvent and temperature effects on the rate of dark thermal reaction of the photoinduced form of compounds $1 a, b$

\begin{tabular}{|c|c|c|c|c|}
\hline Compound & Solvent & $\begin{array}{l}\text { Temperature, } \\
T\left({ }^{\circ} \mathrm{C}\right)\end{array}$ & $\begin{array}{l}\text { Rate constant }{ }^{a}, \\
k\left(\min ^{-1}\right) \text { or } \\
\left(\mathrm{M} \times \min ^{-1}\right)\end{array}$ & $\begin{array}{l}\text { Half-life } \\
\text { period }^{b}, \\
\tau_{1 / 2}(\min )\end{array}$ \\
\hline \multirow[t]{17}{*}{$1 \mathrm{a}$} & \multirow[t]{5}{*}{$\mathrm{EtOH}$} & 10 & 0.083 & 8.3 \\
\hline & & 15 & 0.180 & 3.9 \\
\hline & & 20 & 0.351 & 2.0 \\
\hline & & 25 & 0.708 & 1.0 \\
\hline & & 30 & 1.381 & 0.5 \\
\hline & \multirow[t]{6}{*}{$\mathrm{MeCN}$} & 10 & $0.38 \times 10^{-6}$ & 24.1 \\
\hline & & 15 & $0.76 \times 10^{-6}$ & 12.2 \\
\hline & & 20 & $1.46 \times 10^{-6}$ & 6.3 \\
\hline & & 25 & $2.79 \times 10^{-6}$ & 3.2 \\
\hline & & 30 & $4.98 \times 10^{-6}$ & 1.8 \\
\hline & & 35 & $8.95 \times 10^{-6}$ & 1.0 \\
\hline & \multirow[t]{6}{*}{ 1,4-Dioxane } & 35 & 0.009 & 75.7 \\
\hline & & 40 & 0.017 & 41.1 \\
\hline & & 45 & 0.030 & 23.2 \\
\hline & & 50 & 0.057 & 12.1 \\
\hline & & 55 & 0.102 & 6.8 \\
\hline & & 60 & 0.175 & 4.0 \\
\hline \multirow[t]{19}{*}{$1 b$} & \multirow[t]{7}{*}{ EtOH } & 5 & 0.144 & 4.8 \\
\hline & & 10 & 0.296 & 2.3 \\
\hline & & 15 & 0.626 & 1.1 \\
\hline & & 20 & 1.354 & 0.5 \\
\hline & & 25 & 2.679 & 0.3 \\
\hline & & 30 & 4.947 & 0.2 \\
\hline & & 35 & 8.778 & 0.1 \\
\hline & \multirow[t]{6}{*}{$\mathrm{MeCN}$} & 10 & $0.35 \times 10^{-6}$ & 19.7 \\
\hline & & 15 & $0.69 \times 10^{-6}$ & 10.1 \\
\hline & & 20 & $1.48 \times 10^{-6}$ & 4.7 \\
\hline & & 25 & $2.64 \times 10^{-6}$ & 2.7 \\
\hline & & 30 & $4.82 \times 10^{-6}$ & 1.6 \\
\hline & & 35 & $8.51 \times 10^{-6}$ & 0.9 \\
\hline & \multirow[t]{6}{*}{ 1,4-Dioxane } & 20 & 0.091 & 7.6 \\
\hline & & 25 & 0.182 & 3.8 \\
\hline & & 30 & 0.347 & 2.0 \\
\hline & & 35 & 0.624 & 1.1 \\
\hline & & 40 & 0.997 & 0.7 \\
\hline & & 45 & 1.792 & 0.4 \\
\hline
\end{tabular}

${ }^{a}$ For first-order reactions in ethanol and 1,4-dioxane $\left(\mathrm{min}^{-1}\right)$, for pseudo-zero order reactions in acetonitrile $\left(\mathrm{M} \times \mathrm{min}^{-1}\right) .{ }^{b}$ The halflife period $\left(\tau_{1 / 2}\right)$ was estimated as $0.693 / k$ for first-order reactions in ethanol and 1,4-dioxane, and as $A_{\mathrm{PSS}} / 2 k$ for pseudo-zero order reactions in acetonitrile. 


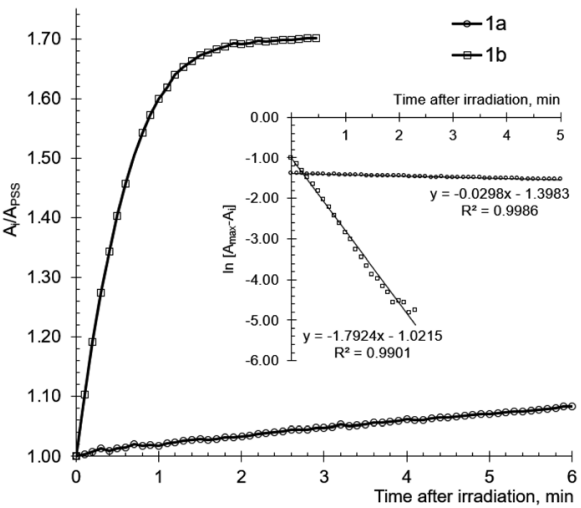

Fig. 4 Kinetics of the reverse thermal transformation for the compounds $1 \mathrm{a}$ (circles) and $1 \mathrm{~b}$ (squares), the plot of fitting the concentration of photo-induced form in a first-order kinetic equation in 1,4-dioxane at $45^{\circ} \mathrm{C}\left(\mathrm{C}=2.5 \times 10^{-5} \mathrm{M}\right)$.

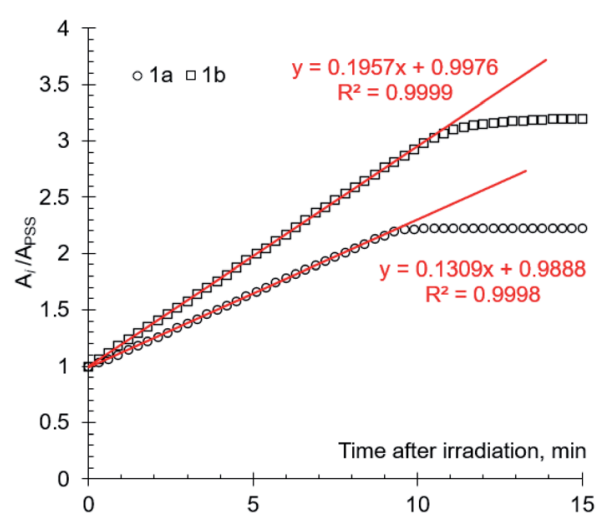

Fig. 5 Kinetics of the reverse thermal transformation of compound $1 \mathrm{a}$ (circles) and $1 \mathrm{~b}$ (squares) in $\mathrm{MeCN}\left(\mathrm{C}=2.5 \times 10^{-5} \mathrm{M}, 20^{\circ} \mathrm{C}\right.$ ).

$45{ }^{\circ} \mathrm{C}$. It should be noted, that kinetics of the reverse thermal reactions of photochromes $\mathbf{1 a}, \mathbf{b}$ in ethanol (Fig. 3B) and 1,4dioxane (Fig. 4) were fitted to the first-order equation at each of the studied temperatures.

Acetonitrile solutions of compounds 1a,b demonstrated a comparable with ethanol temperature effect on the rate of the dark reverse reaction. Thus, the half-life period $\left(\tau_{1 / 2}\right)$ of furan derivative $\mathbf{1 b}$ changes from $19.7 \mathrm{~min}$ to $1.6 \mathrm{~min}$ ranging the temperature from 10 to $30{ }^{\circ} \mathrm{C}$ (Table 2). At the same time, dark thermal reaction in acetonitrile fits to a pseudo-zero order
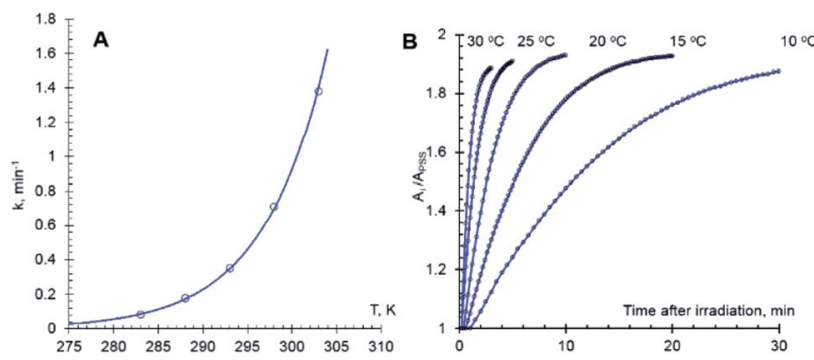

Fig. 6 Temperature effect on the rate constant of the dark thermal relaxation of compound $1 \mathrm{a}$ in ethanol (A); absorbance changes of compound $1 \mathrm{a}$ in ethanol after irradiation by visible light vs. time at various temperatures (B).

kinetic equation (Fig. 5) regardless the temperature and the type of heterocyclic unit of compounds 1 .

It is worth mentioning that pseudo-zero reaction order is usually not observed in solutions; therefore, the obtained data are rather unique example. Zero-order reactions are usually found for heterogeneous or enzyme catalyzed processes. ${ }^{32-36}$ The presence of a rate-limiting step allowing only a small fraction of the reactant molecules to react is typical for such reactions. Thus, the reactant conversion occurs with constant rate and therefore the true reaction order is hidden.

In the case of compounds $\mathbf{1}$, pseudo-zero reaction order is apparently caused by low deprotonation rate of the photoinduced $\mathrm{CH}$-acid $\mathbf{1 S}$ in acetonitrile (Scheme 2), since MeCN is a protonophobia solvent and poorly solvates anions. ${ }^{37}$ In such solvent as acetonitrile deprotonation of the photoinduced $\mathrm{CH}^{-}$ acid $1 \mathrm{~S}$ becomes a rate-limiting step of the dark reverse reaction unlike other solvents where the reaction rate directly associated with anion $\mathbf{1 S}^{-}$concentration. Therefore, in acetonitrile deprotonation process is followed by the immediate consumption of $\mathbf{1 S}^{-}$and the ring-opening occurs with a constant rate.

The discovery of novel zero-order processes is significant, because such a system could be used, for example, for prolonged drug delivery. ${ }^{38,39}$

\subsection{Calculation of activation parameters for the thermal relaxation of the photoinduced form}

The obtained data on the temperature effect on the dark thermal reaction rate of the photoinduced form of compounds 1 made it possible to estimate the activation energy and other thermodynamic parameters of this process for the first time.

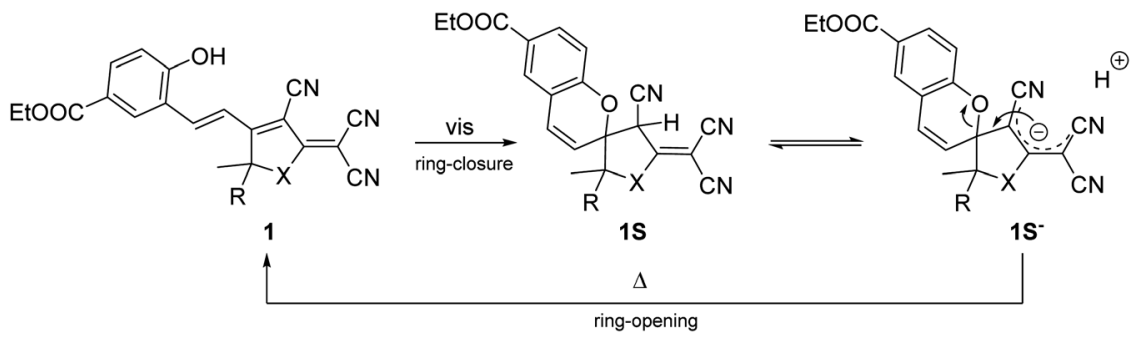

Scheme 2 A possible scheme of photochromic transformations of compounds 1a,b. 
Table 3 Thermodynamic parameters of the thermal relaxation of compounds $1 a, b$

\begin{tabular}{|c|c|c|c|c|c|}
\hline Comp. & Solvent & $E_{\mathrm{a}}\left(\mathrm{kJ} \mathrm{mol}^{-1}\right)$ & $\Delta H^{\neq}\left(\mathrm{kJ} \mathrm{mol}^{-1}\right)$ & $\Delta S^{\neq}\left(\mathrm{J} \mathrm{K}^{-1} \mathrm{~mol}^{-1}\right)$ & $A\left(\mathrm{~s}^{-1}\right)$ \\
\hline \multirow[t]{2}{*}{$1 \mathbf{a}$} & EtOH & 99.6 & 97.2 & 44.3 & $3.40 \times 10^{15}$ \\
\hline & 1,4-Dioxane & 101.4 & 98.7 & 2.2 & $2.37 \times 10^{13}$ \\
\hline & 1,4-Dioxane & 91.3 & 88.8 & 4.7 & $3.02 \times 10^{13}$ \\
\hline
\end{tabular}

Fig. 6A demonstrates an exponential dependence of the reverse reaction rate constant on temperature. Fig. $6 \mathrm{~B}$ also shows the relationship between the absorbance increasing rate of solution 1a in ethanol after visible light irradiation and time at various temperatures.

The activation energy $\left(E_{\mathrm{a}}\right)$ and frequency factor $(A)$ were calculated from the experimental dark reverse reaction rate constant $k$ values by the Arrhenius equation (eqn (1)), where $R$ is the universal gas constant and $T$ is the absolute temperature. These obtained data are collected in the Table 3. The Arrhenius plot (Fig. 7A) shows a good correlation for both photochromes 1 in different solvents.

$$
\ln k=\ln A-\frac{E_{\mathrm{a}}}{R T}
$$

The activation enthalpy $\left(\Delta H^{\neq}\right)$and the activation entropy $\left(\Delta S^{\neq}\right)$were calculated by the Eyring equation, where $k_{\mathrm{B}}$ and $h$ are the Bolzmann and Planck constants, respectively.
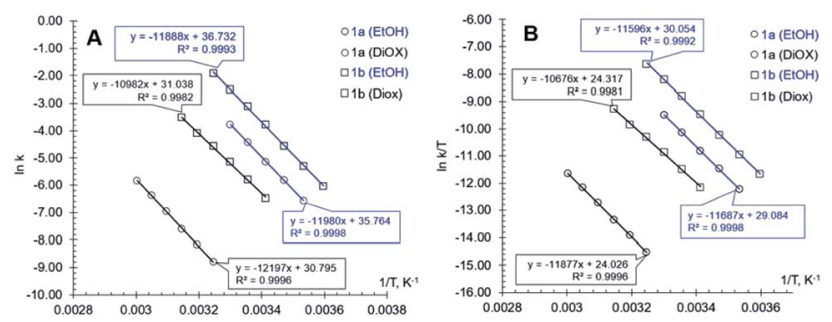

Fig. 7 Arrhenius (A) and Eyring (B) plots for compounds 1a (circles) and $1 \mathrm{~b}$ (squares) in ethanol (blue) and 1,4-dioxane (black) $\left(C=2.5 \times 10^{-5} \mathrm{M}\right)$.

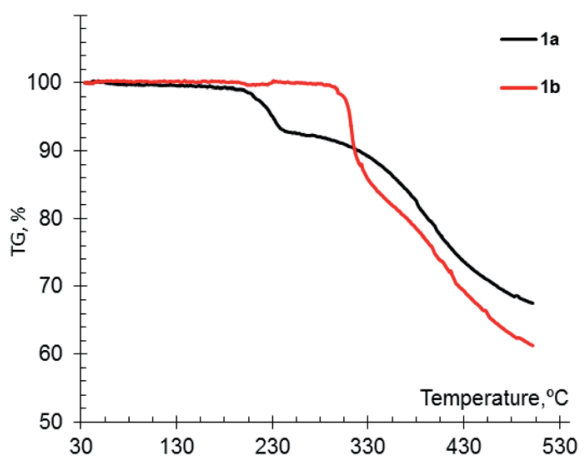

Fig. 8 TGA curves of compounds $1 \mathrm{a}$ and $1 \mathrm{~b}$ at the heating rate of $10{ }^{\circ} \mathrm{C} \mathrm{min}^{-1}$ under an argon atmosphere.

$$
\ln \frac{k}{T}=\frac{-\Delta H^{\neq}}{R T}+\ln \frac{k_{\mathrm{B}}}{h}+\frac{\Delta S^{\neq}}{R}
$$

Fig. 7B shows the Eyring plot with an excellent linearity. We have found that, depending on the solvent and type of the nitrile-rich heterocycle, the activation energy is in the range from 91.3 to $101.4 \mathrm{~kJ} \mathrm{~mol}^{-1}$ (Table 3). The activation enthalpy of the studying process is in the range of $88.8-98.7 \mathrm{~kJ} \mathrm{~mol}^{-1}$. More significant differences have been found for the activation entropy values. For the dark reaction in ethanol $\Delta S^{\neq}$is 44.3$52.3 \mathrm{~J} \mathrm{~K}^{-1} \mathrm{~mol}^{-1}$, while in 1,4-dioxane it is much less, namely 2.2-4.7 $\mathrm{J} \mathrm{K}^{-1} \mathrm{~mol}^{-1}$. A similar dependence has been also shown for the frequency factor $(A)$, it is significantly lower in 1,4dioxane. The obtained $A$ and $\Delta S^{\neq}$values are consistent with the observed lower $\tau_{1 / 2}$ of photo-induced form in ethanol.

Data on acetonitrile solutions were not included in the calculations of activation parameters, because the kinetics of reverse thermal process fit to the pseudo-zero order equation and the observed rate constants are not comparable with rate constants of reactions occurred in ethanol and 1,4-dioxane.

\subsection{Thermal stability of the initial state in an individual form}

A thermal stability of the initial state of NRP structures in an individual form is another completely unrevealed issue. This parameter is one of the most important ones for organic chromophores when they are considering for practical application. It demonstrates the acceptable temperature range for compound in which it can be used.

In this regard, we evaluated the thermal stability of the synthesized NRP derivatives 1a,b using thermogravimetric analysis for the first time. It was found that furan $\mathbf{1 b}$ did not undergo any significant changes upon heating up to $300{ }^{\circ} \mathrm{C}$ in an argon atmosphere. A weight loss of $10.4 \%$ occurred in the range of $300-320{ }^{\circ} \mathrm{C}$ which was accompanied by melting with decomposition (Fig. 8). Pyrrole 1a showed lower thermal stability. It underwent a thermal decomposition in the range of 200-245 ${ }^{\circ} \mathrm{C}$ with a $6.2 \%$ weight loss. Such a difference of the TGA curves was probably associated with the presence of a labile aminoalcohol moiety in the structure of pyrrole $\mathbf{1 a}$.

\section{Experimental}

\subsection{Materials and methods}

The progress of reactions and the purity of products were monitored by TLC on Sorbfil plates (spots were visualized under 
UV light, by treatment with iodine vapor, or by heating). The IR spectra were recorded on an FSM-2201 spectrometer with Fourier transform from samples dispersed in mineral oil. The NMR spectra were measured in DMSO- $d_{6}$ on Bruker DRX-500 spectrometer using tetramethylsilane as an internal reference. Elemental analyses were performed using a FlashEA $1112 \mathrm{CHN}$ analyzer. The mass spectra were obtained on a mass spectrometer Finnigan MAT INCOS-50. The UV spectra were recorded on an Agilent Cary 60 UV-Vis Spectrophotometer. Kinetic data of the dark thermal reaction were recorded at different thermostat temperatures using Peltier cell holder accessory. To study the photochromic behavior of compounds, the solutions were irradiated with non-filtered visible light by LED XM-LT6 CREE (spectral range of 400-700 nm, a luminous power density equal to $205 \mathrm{~mW} \mathrm{~cm}^{-2}$ ). Thermogravimetric analysis was performed on a simultaneous thermogravimetry/ differential thermal analyzer Shimadzu DTG-60. The syntheses of the starting compounds $\mathbf{2 a , b}$ were carried out according to the described procedures. ${ }^{\mathbf{4 0 , 4 1}}$

\subsection{Synthesis of ethyl (E)-3-(2-(4-cyano-5- (dicyanomethylene)-2,2-dimethyl-2,5-dihydrofuran-3-yl)vinyl)- 4-hydroxybenzoate $1 \mathrm{~b}$}

$0.194 \mathrm{~g}$ (1 mmol) of ethyl 3-formyl-4-hydroxybenzoate and $77 \mathrm{mg}$ ( $1 \mathrm{mmol}$ ) of ammonium acetate were added to a suspension of $0.199 \mathrm{~g}$ ( $1 \mathrm{mmol})$ of TCF in $3 \mathrm{~mL}$ of $96 \%$ ethanol under argon atmosphere. The resulting mixture was stirred at room temperature for $10 \mathrm{~h}$ until the complete consumption of TCF monitored by TLC. The obtained solid product was filtered off, washed 3 times by $2 \mathrm{~mL}$ of ethanol and then dried in a vacuum drying cabinet ( 1 torr) over $\mathrm{CaCl}_{2}$ for 3 days.

\subsection{Spectral characterization of compounds $\mathbf{1 b}$}

Yellow solid; mp $311-312{ }^{\circ} \mathrm{C}$ (dec.); yield 76\%. IR (mineral oil, $\left.\nu, \mathrm{cm}^{-1}\right): 3305(\mathrm{OH}), 2230,2214(\mathrm{C} \equiv \mathrm{N}), 1694(\mathrm{C}=\mathrm{O}), 1589(\mathrm{C}=$ C), 1279 (CO). ${ }^{1} \mathrm{H}$ NMR (500.13 MHz, DMSO- $\left.d_{6}\right) \delta: 1.32(3 \mathrm{H}, \mathrm{t}, J=$ $\left.7.1 \mathrm{~Hz}, \mathrm{OCH}_{2} \mathrm{CH}_{3}\right), 1.81\left(6 \mathrm{H}, \mathrm{s}, 2 \mathrm{CH}_{3}\right), 4.31(2 \mathrm{H}, \mathrm{t}, J=7.1 \mathrm{~Hz}$, $\left.\mathrm{OCH}_{2} \mathrm{CH}_{3}\right), 7.05\left(1 \mathrm{H}, \mathrm{d}, J=8.6 \mathrm{~Hz}, \mathrm{C}_{6} \mathrm{H}_{3}\right), 7.64(1 \mathrm{H}, \mathrm{d}, J=$ $16.5 \mathrm{~Hz}, \mathrm{CH}=), 7.93\left(1 \mathrm{H}, \mathrm{dd}, J=2.2,8.6 \mathrm{~Hz}, \mathrm{C}_{6} \mathrm{H}_{3}\right), 8.07(1 \mathrm{H}, \mathrm{d}, J$ $=16.5 \mathrm{~Hz}, \mathrm{CH}=), 8.42\left(1 \mathrm{H}, \mathrm{d}, J=2.2, \mathrm{~Hz}, \mathrm{C}_{6} \mathrm{H}_{3}\right), 11.83(1 \mathrm{H}, \mathrm{s}$, $\mathrm{OH}) .{ }^{13} \mathrm{C}$ NMR $\left(125.76 \mathrm{MHz}, \mathrm{DMSO}-d_{6}\right) \delta: 14.32,25.29,54.25$, 60.59, 99.10, 99.33, 111.02, 111.91, 112.74, 116.77, 117.04, 121.33 , 121.53, 133.65, 134.21, 143.63, 162.25, 165.11, 176.31, 177.08. MS, (EI, $70 \mathrm{eV}): m / z(\%) 375[\mathrm{M}]^{+}(48), 360[\mathrm{M}-\mathrm{Me}]^{+}(22)$, 290 (100). Anal. calcd for $\mathrm{C}_{21} \mathrm{H}_{17} \mathrm{~N}_{3} \mathrm{O}_{4}: \mathrm{C}, 67.19 ; \mathrm{H}, 4.56 ; \mathrm{N}$, 11.19. Found: C, 67.01; H, 4.66; N, 11.04 .

\section{Conclusions}

Thus, visible-light-sensitive representatives of NRP photochromes bearing an ester group were synthesized. The temperature effect on the rate of thermal relaxation of the photoinduced form in various solvents was described for the first time for these compounds. Regardless the temperature the first order kinetics of the reverse thermal reaction was observed in ethanol and 1,4-dioxane, while an unusual pseudo-zero kinetics was registered in acetonitrile solution. Using the Arrhenius and Eyring equations the activation energy of this process as well as the thermodynamic parameters, such as entropy and enthalpy of the activation were calculated. A higher temperature stability of the initial state of the furan derivative in an individual form was shown in comparison with pyrrole containing NRP. The obtained data indicated wide possibilities for varying the thermal stability of NRP derivatives by changing both the structure of the photochrome and the used solvent.

\section{Conflicts of interest}

There are no conflicts to declare.

\section{Acknowledgements}

The research was performed with the financial support of the Russian Science Foundation (grant no. 18-73-10065).

\section{Notes and references}

1 Y. Wakayama, R. Hayakawa, K. Higashiguchi and K. Matsuda, J. Mater. Chem. C, 2020, 8, 10956.

2 L. Wang and Q. Li, Chem. Soc. Rev., 2018, 47, 1044.

3 H. Nie, J. L. Self, A. S. Kuenstler, R. C. Hayward and J. Read de Alaniz, Adv. Opt. Mater., 2019, 7, 1900224.

4 L. Dong, Y. Feng, L. Wang and W. Feng, Chem. Soc. Rev., 2018, 47, 7339.

5 T. Fukaminato, S. Ishida and R. Métivier, NPG Asia Mater., 2018, 10, 859.

6 Z. Li, C. He, Z. Lu, P. Li and Y.-P. Zhu, Dyes Pigm., 2020, 182, 108623.

7 Z. L. Pianowski, Chem.-Eur. J., 2019, 25, 5128.

8 H. Cheng, J. Yoon and H. Tian, Coord. Chem. Rev., 2018, 372, 66.

9 S. Jia, W.-K. Fong, B. Graham and B. J. Boyd, Chem. Mater., 2018, 30, 2873.

10 S. Aiken, R. J. L. Edgar, C. D. Gabbutt, B. M. Heron and P. A. Hobson, Dyes Pigm., 2018, 149, 92.

11 V. A. Barachevsky, Rev. J. Chem., 2017, 7, 334.

12 M. Kathan and S. Hecht, Chem. Soc. Rev., 2017, 46, 5536.

13 V. Kumar Gupta, in Dyes Pigm., [Working Title], IntechOpen, 2021.

14 A. Bianco, S. Perissinotto, M. Garbugli, G. Lanzani and C. Bertarelli, Laser Photonics Rev., 2011, 5, 711.

15 H. Görner, Phys. Chem. Chem. Phys., 2001, 3, 416.

16 M. Zanoni, S. Coleman, K. J. Fraser, R. Byrne, K. Wagner, S. Gambhir, D. L. Officer, G. G. Wallace and D. Diamond, Phys. Chem. Chem. Phys., 2012, 14, 9112.

17 J. Liu, A. K.-W. Chan, M. Ng, E. Y.-H. Hong, N. M.-W. Wu, L. Wu and V. W.-W. Yam, Organometallics, 2019, 38, 3542.

18 D. L. Isac, A. Airinei, M. Homocianu, N. Fifere, C. Cojocaru and C. Hulubei, J. Photochem. Photobiol., A, 2020, 390, 112300.

19 G. Angelini, C. Campestre, L. Scotti and C. Gasbarri, Molecules, 2017, 22, 1273. 
20 D. Kitagawa, T. Nakahama, Y. Nakai and S. Kobatake, J. Mater. Chem. C, 2019, 7, 2865.

21 K. Inaba, R. Iwai, M. Morimoto and M. Irie, Photochem. Photobiol. Sci., 2019, 18, 2136.

22 K. Ayub and R. H. Mitchell, J. Org. Chem., 2014, 79, 664.

23 S. A. Ahmed, N. El Guesmi, B. H. Asghar, F. Maurel, I. I. Althagafi, K. S. Khairou and H. A. Muathen, J. Phys. Org. Chem., 2016, 30, e3614.

24 V. Lokshin, L. Bekere and V. Khodorkovsky, Dyes Pigm., 2017, $145,570$.

25 V. K. Johns, P. Peng, J. DeJesus, Z. Wang and Y. Liao, Chem.Eur. J., 2014, 20, 689.

26 C. Yang, T. Khalil and Y. Liao, RSC Adv., 2016, 6, 85420.

27 M. Yu. Belikov, M. Yu. Ievlev, S. V. Fedoseev and O. V. Ershov, New J. Chem., 2020, 44, 6121.

28 M. Yu. Belikov, M. Yu. Ievlev, S. V. Fedoseev and O. V. Ershov, Res. Chem. Intermed., 2020, 46, 3477.

29 M. Yu. Belikov, M. Yu. Ievlev, S. V. Fedoseev and O. V. Ershov, New J. Chem., 2019, 43, 8414.

30 M. Yu. Belikov, M. Yu. Ievlev, S. V. Fedoseev and O. V. Ershov, Res. Chem. Intermed., 2019, 45, 4625.
31 M. Yu. Belikov, S. V. Fedoseev, M. Yu. Ievlev, O. V. Ershov, K. V. Lipin and V. A. Tafeenko, Synth. Commun., 2020, 50, 2413.

32 Y. Chen and Y.-F. Song, ChemPlusChem, 2013, 79, 304.

33 J. P. Lopes, S. S. S. Cardoso and A. E. Rodrigues, AIChE J., 2009, 55, 2686.

34 G. R. Warner, Y. Somasundar, C. Weng, M. H. Akin, A. D. Ryabov and T. J. Collins, Chem.-Eur. J., 2020, 26, 7631.

35 D. Yu. Murzin, Catal. Commun., 2008, 9, 1815.

36 Y. Ji, Y. Shi, Y. Yang, P. Yang, L. Wang, J. Lu, J. Li, L. Zhou, C. Ferronato and J.-M. Chovelon, J. Hazard. Mater., 2019, 361, 152.

37 J. F. Coetzee, in Progress in Physical Organic Chemistry, John Wiley \& Sons, Inc., 2007, pp. 45-92.

38 M.-L. Laracuente, M. H. Yu and K. J. McHugh, J. Controlled Release, 2020, 327, 834.

39 Y. Li, Y. Liu, R. Ma, Y. Xu, Y. Zhang, B. Li, Y. An and L. Shi, ACS Appl. Mater. Interfaces, 2017, 9, 13056.

40 W. E. Moerner, R. J. Twieg, D. W. Kline and M. He, US Pat., 134737, 2007.

41 M. Yu. Belikov, S. V. Fedoseev, M. Yu. Ievlev and O. V. Ershov, Synth. Commun., 2018, 48, 2850. 